\title{
Extragenital Endometriosis; A Rare Casue of Sciatica: A Case Report
}

\author{
Duygu GELER KÜLCÜ1, Gülcan ÖZTÜRK², Neslihan TAŞDELEN³, Ece AYDOĞ² \\ ${ }^{\prime}$ Clinic of Physical Medicine and Rehabilitation, Fatih Sultan Mehmet Training and Research Hospital, Istanbul, Turkey \\ ${ }^{2}$ Clinic of Physical Medicine and Rehabilitation, Yeditepe University Hospital, Istanbul, Turkey \\ ${ }^{3}$ Clinic of Radiology, Yeditepe University Hospital, Istanbul, Turkey
}

\begin{abstract}
Endometriosis is a common disease characterized by the presence of endometrial tissue outside the uterus, such as over, colon, nasal mucosa. Furthermore, it can affect sciatic nerve as a rare presentation causing cyclic sciatica, chronic pelvic pain, paresis, and paresthesia. Early diagnosis and treatment is very important to minimize the nerve damage caused by endometrial focus on sciatic nerve. Diagnosis of sciatica due to endometriosis can be made by magnetic resonance neurography (MRN), thereby identifying abnormalities of the sciatic nerve in patients with unexplained sciatica. MRN is a sensitive tool for evaluating both the lumbosacral plexus and sciatic nerve. We described a 38-year-old female patient with cyclic sciatica for 4 years. She had an endometrial focus compressing sciatic nerve at left sciatic foramen level that was diagnosed by MRN. In this case report, we aimed to underline the importance of appropriate diagnostic tools in the patients with extraspinal sciatica.

Keywords: Magnetic resonance neurography, extraspinal sciatica
\end{abstract}

\section{Introduction}

Sciatica is a common disease caused by intraspinal or extraspinal pathologic processes along the lumbar nerve roots and sciatic nerve (1). Most frequent intraspinal disorder is disc herniations. However, the extraspinal causes peripheral schwannomas, piriformis syndrome, and extrapelvic endometriosis may mimic lumbar disc herniations and may be an important unrecognized etiology (2). In this case report, we presented a patient with sciatica caused by endometrial focus in left sciatic nerve foramen. We aimed to underline the importance of physical examination, detailed patient history in patients with radicular pain to guide appropriate treatment.

\section{Case Report}

A 38-year-old female patient with low back and left leg pain was referred to Physical Medicine and Rehabilitation (PMR) outpatient clinic by Neurosurgery Department. By Neurosurgery Department, lumbar magnetic resonance imaging (MRI) and electroneuromyography were obtained. MRI revealed L5/ $\mathrm{S} 1$ lumbar disc protrusion. There was no root compression. The electroneuromyography revealed no abnormality. They suggested the patient to refer to our department to receive conservative treatment. According to the patient's history, duration of symptoms was 4 years. The pain was initially limited to menstrual periods. In the last 2 years, pain worsened and pain-free intervals were shortened. Pain increased by sitting for a long

This study was presented in $5^{\text {th }}$ Turkish Rheumatology Congress as poster presentation (27-31 March 2012, Antalya, Turkey).

Address for Correspondence: Gülcan Öztürk, MD, Gebze Fatih Devlet Hastanesi, Fiziksel Tıp ve Rehabilitasyon Kliniği, Kocaeli, Türkiye. Phone: +90216578 4039 E-mail: drgul_can@hotmail.com

Received: January 2014 Accepted: March 2014

OCopyright 2015 by Turkish Society of Physical Medicine and Rehabilitation - Available online at www.ftrdergisi.com

Cite this article as: 
duration. There was no association with movement. Her visual analog scale (VAS) was 8 . There was no history of trauma.

On her physical examination, there was left gluteal sciatic notch tenderness. Range of motion of the lumbosacral spine was minimally limited and mildly painful in all directions. Straight leg test, pace sign, and Freiberg's sign were positive on the left side. FABER and FADIR tests were bilaterally negative. On sensory examination, there was hypoesthesia on the left S1 dermatome. Deep tendon reflexes were normoactive. Strength of the lower extremity muscles were $5 / 5$.

The patient had symptoms and clinical findings of sciatica. According to the history and physical examination, the only etiologic factor not considered was lumbar disc herniation (LDH). Extraspinal sciatic neuropathy due to compressive pathologic process, such as piriformis syndrome or endometriosis in pelvic or extrapelvic region, was suspected. Pelvic MRN was performed on the second day of menstruation to confirm the prediagnosis. Magnetic resonance neurography of the pelvis demonstrated multilocule hemorrhagic cystic lesion compressing sciatic nerve at the left sciatic foramen level, which had a diameter of $18 \mathrm{~mm}$. There was no contrast enhancement after giving intravenous contrast agent. Magnetic resonance neurography confirmed the suspicion of extragenital endometriosis (Figure 1, 2).

The patient was consulted to the gynecology specialist. Extragenital endometriosis was not histologically confirmed because the patient did not accept surgical exploration. Combined oral contraceptive medication, leuprolide acetate $3.75 \mathrm{mg} /$ month intramusculer, was initiated.

After 1 month follow-up, at menstrual cycle, she had similar symptoms with less intensity. Her VAS score decreased from 8 to $2-3$. The patient was comfortable after prolonged sitting. There was no tenderness on the left gluteal notch. Freiberg's sign and Pace sign became negative. After 6 months follow-up she had cyclic siatica with very low intensity. She reported that her daily living life was not disturbed because of pain. Here we report a case of extragenital endometriosis after we obtained the informed consent of the patient.

\section{Discussion}

Endometriosis is a common disease characterized by the presence of endometrial tissue outside the uterus such as over, colon, and nasal mucosa $(3,4)$. Common clinical presentations are dysmenorrhea, infertility, dyspareunia, or can be asymptomatic (4). Endometriosis of the sciatic nerve is a rare presentation (5), manifesting as cyclic sciatica. In reproductive-age women presenting with sciatica of unknown genesis, endometriosis must be considered (3). In recent literature, sciatica caused by endometriosis has been presented $(3,4,6)$.

Diagnosis of sciatica due to endometriosis can be made by an association of symptoms to menstrual periods and MRI findings. Because the signal intensity is due to time of bleeding, MRI should be taken at the time of bleeding. In this case report, timing of MRN has been set up according to the patient's menstrual cycle.

Sometimes MRI demonstrates positive findings in 65\%-75\% (7); however, a significant percentage of those positive findings

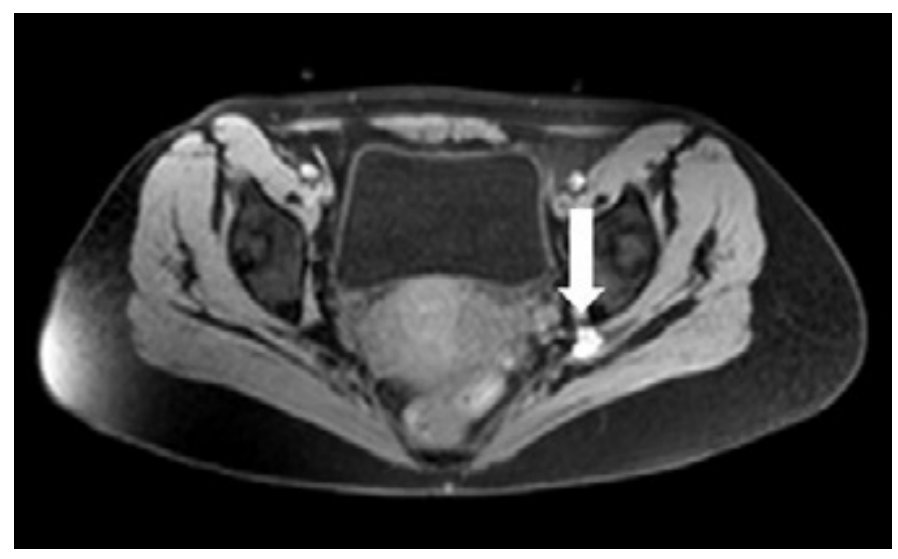

Figure 1. On fat-saturated T1 weighted image, hyperintense lesion is observed next to the sciatic nerve (White arrow)
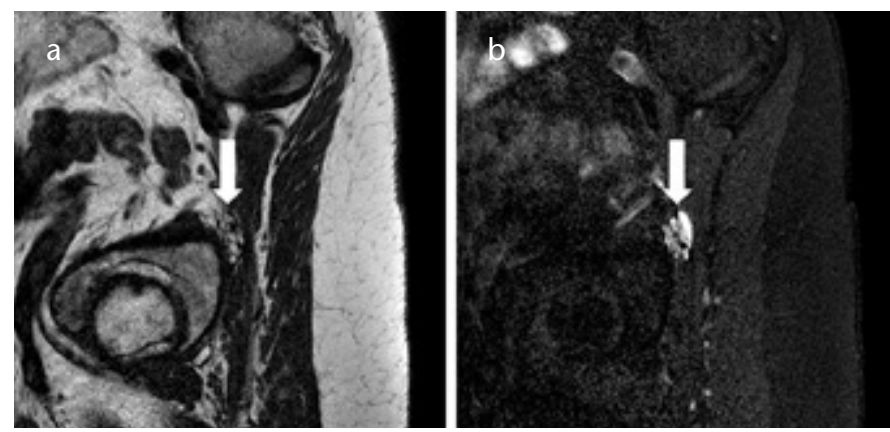

Figure 2. a, b. The lesion is hyperintense on both T1 weighted (a) and fat-saturated T2 weighted (b) paracoronal oblique images (White arrow)

are coincidental and not etiological (8). In this case, the patient was diagnosed as LDH and referred to PMR. However, LDH was coincidental. The coincidence may cause delayed treatment as presented in this case report.

For patients with sciatica resulting from extraforaminal lesions, the cause of pain generally can not be revealed by lumbar spine MRI. Conversely, MRN is a sensitive tool for evaluating both the lumbosacral plexus and sciatic nerve. The spectrum of abnormal plexus and sciatic nerve anatomic findings is myriad and includes fibrous entrapment, muscular entrapment, vascular compression, posttraumatic lesions, and ischemic neuropathy (9). In a recent study, Lewis et al. (6) aimed to demonstrate sciatic nerve entrapment by the piriformis muscle and revealed that MRN allows more accurate diagnosis of extraspinal sciatica, such as the piriformis syndrome. Pham et al. (10) demonstrated diffuse infiltrative lesion of endometriosis at the sciatic notch in a patient with cyclic sciatica.

Magnetic Resonance Neurography provides high-resolution images to demonstrate entrapment of the nerve and morphological changes in the nerve (8). The trajectory of the nerves is well visualized on maximum-intensity-projection images (11). The T-1 weighted MRN sequences present anatomic detail, and T-2 weighted sequences present abnormal nerve signal intensity. Enlargement of a nerve is a definite evidence of abnormality 
$(2,5,9)$. In this case report, MRN revealed multilocule hemorrhagic cystic lesion compressing sciatic nerve at the left sciatic foramen level that had diameter of $18 \mathrm{~mm}$. There was no contrast enhancement after giving intravenous contrast agent. Hemorrhagic cystic schwannom was excluded because of no contrast enhancement. MRN findings were considered as endometriosis by the radiologist.

Early diagnosis and treatment is very important to minimize the nerve damage caused by recurrent cycles of bleeding and fibrosis. Endometriosis causes nerve damage by cyclic inflammation and advancing implanted ectopic uterine tissue into the epineurium and perineurium (4). Endometriosis treatment includes pain control, hormone therapy, and surgery (12). Our patient was treated by hormone therapy.

\section{Conclusion}

This case report underlined the importance of physical examination and detailed patient history in patients with radicular pain to guide appropriate diagnostic tools and treatment.

Informed Consent: Verbal informed consent was obtained from the patient who participated in this case.

Peer-review: Externally peer-reviewed.

Author Contributions: Concept - D.G.K.; Design - D.G.K., G.Ö.; Supervision - E.A.; Resource - D.G.K.; Materials - G.Ö., N.T.; Data Collection and/or Processing - N.T.; Analysis and/or Interpretation - D.G.K, N.T.; Literature Review - G.Ö.; Writer - D.G.K., G.Ö.; Critical Review - E.A.; Other - E.A.

Conflict of Interest: No conflict of interest was declared by the authors.

Financial Disclosure: The authors declared that this study has received no financial support.

\section{References}

1. Kulcu DG, Naderi S. Differential diagnosis of intraspinal and extraspinal non-discogenic sciatica. J Clin Neurosci 2008; 15:1246-52. [CrossRef]

2. Kralick F, Koenigsberg R. Sciatica in a patient with unusual peripheral nerve sheath tumors. Surg Neurol 2006;66:634-7. [CrossRef]

3. Ceccaroni M, Clarizia R, Cosma S, Pesci A, Pontrelli G, Minelli L. Cyclic sciatica in a patient with deep monolateral endometriosis infiltrating the right sciatic nerve. J Spinal Disord Tech 2011;24:474-8. [CrossRef]

4. Teixeira AB, Martins WA, d'Ávila R, Stochero L, Alberton L, Bezerra $S$, et al. Endometriosis of the sciatic nerve. Arq Neuropsiquiatr 2011;69:995-6. [CrossRef]

5. Baker GS, Parsons WR, Welch JS. Endometriosis within the sheath of the sciataic nerve. J Neurosurg 1966;25:652-5. [CrossRef]

6. Lewis AM, Layzer R, Engstrom JW, Barbaro NM, Chin CT. Magnetic resonance neurography in extraspinal sciatica. Arch Neurol 2006;63:1469-72. [CrossRef]

7. Alaranta $H$, Hurme $M$, Einola $S$, Falck B, Kallio V, Knuts LR, et al. A prospective study of patients with sciatica. A comparison between conservatively treated patients and patients who have undergone operation, part II: results after one year follow-up. Spine (Phila Pa 1976) 1990;15:1345-9. [CrossRef]

8. Filler AG, Haynes J, Jordan SE, Prager J, Villablanca JP, Farahani K, et al. Sciatica of nondisc origin and piriformis syndrome: diagnosis by magnetic resonance neurography and interventional magnetic resonance imaging with outcome study of resulting treatment. J Neurosurg Spine 2005;2:99-115. [CrossRef]

9. Moore KR, Tsuruda JS, Dailey AT. The value of MR neurography for evaluating extraspinal neuropathic leg pain: a pictorial essay. AJNR Am J Neuroradiol 2001;22:786-94.

10. Pham M, Sommer C, Wessig C, Monoranu CM, Pérez J, Stoll G, et al. Magnetic resonance neurography for the diagnosis of extrapelvic sciatic endometriosis. Fertil Steril 2010;94:351. [CrossRef]

11. Takahara T, Hendrikse J, Kwee TC, Yamashita $T$, Van Cauteren $M$, Polders $\mathrm{D}$, et al. Diffusion-weighted MR neurography of the sacral plexus with unidirectional motion probing gradients. Eur Radiol 2010;20:1221-6. [CrossRef]

12. Fraser IS. Recognizing, understanding and managing endometriosis. J Hum Reprod Sci 2008;1:56-64.[CrossRef] 